\title{
Assessing mechanical loading regimes and fatigue life of marine power cables in marine energy applications ${ }^{1}$
}

\author{
Philipp R. Thies ${ }^{2}$, Lars Johanning ${ }^{2}$, George H. Smith ${ }^{2}$ \\ ${ }^{2}$ CEMPS - College of Engineering, Mathematics and Physical Science \\ Renewable energy research group, University of Exeter \\ Cornwall Campus, Treliever Rd, Penryn, TR10 9EZ, UK.
}

\begin{abstract}
Reliable marine power cables are imperative for the cost-effective operation of marine energy conversion systems. There is considerable experience with marine power cables under static and dynamic load conditions but the loading regimes for floating marine energy converters (MECs) are not well understood, due to the lacking field experience.

This paper aims to assess mechanical load conditions and failure modes for a dynamic power cable that is connected to a floating wave energy converter. The applied approach combines experimental tank test data with numerical modelling and site specific wave characteristics to identify maximum load points and to then quantify the fatigue life. The effect of varying wave parameters on maximum loads and fatigue cycles is investigated and results are presented for two common umbilical configurations, catenary and lazy wave.

In situations with limited field experience, the presented approach provides a tool to determine if critical components are fit for purpose and to assess the expected level of reliability prior to deployment. The estimated cable conductor's fatigue life is estimated for the lazy wave configuration and highlights component fatigue failure as a major concern that needs to be addressed in marine energy applications.
\end{abstract}

Corresponding author: Philipp R. Thies, University of Exeter, Cornwall Campus, Treliever Rd., Penryn TR10 9EZ, UK. Email: P.R.Thies@exeter.ac.uk

\footnotetext{
1 PREPRINT MANUSCRIPT OF AN ARTICLE SUBMITTED TO: SPEC. ISSUE PROC. OF THE INSTITUTION OF MECHANICAL ENGINEERS, PART O, JOURNAL OF RISK AND RELIABILITY
} 


\section{Introduction}

Electricity transmission via subsea power cables has been undertaken by engineers for more than a century and is a well established technology [1]. The large majority of the present applications are static, i.e. the cable is connected to a fixed structure such as a pile or foundation and is not subject to significant cyclic loading. Power cables have also been used in dynamic applications (floating oil and gas platforms, remotely operated vehicles) where they have to withstand considerable cyclic loads induced by the motions of the floating body in combination with wave and current effects $[2,3]$. Due to the cyclic loading dynamic marine power cables are susceptible to fatigue failures. Floating marine energy converters are particularly subject to dynamic and cyclic loading as they are most effective in locations with high wave energy densities and often depend on the wave induced motion for power-take-off purposes [4]. Since the operational parameters of such device will require them to operate close to the forcing wave periods the response will typically be larger than for, say offshore structures where motions are far from the resonant period of the system

The objective of this paper is to assess the potential failure modes and mechanical loads of a typical subsea power cable connected to a floating wave energy converter. In this paper a combined approach is presented, where the measured top-end motion response of a device is obtained from an experimental tank test and is subsequently applied in a numerical model, to assess the mechanical loading and fatigue cycles.

This methodology arises from ongoing and future work undertaken within the research group at the University of Exeter to assess the reliability of marine renewable energy components. The general approach towards component testing and associated test facilities to measure and replicate the dynamic load conditions for floating marine energy devices are described in $[5-7]$.

The paper is organised in four main parts. It first briefly describes the design of marine power cables and their potential failure modes (section 2). It then describes an approach to assess the reliability of marine power cables (section 3). Section 4 presents the response and load 
behaviour, while section 5 provides the reliability assessment with regard to maximum load conditions and fatigue life.

\section{Marine power cable design criteria}

There is a multitude of different designs and configurations of submarine power cables, but a typical marine power cable as shown in Figure 1 comprises of seven layers [1, 2]:

1. Conductor core: This comprises wires made out of either copper or aluminium that carry the electrical current.

2. Electrical insulation: The electrical insulation can be achieved by three different design/material types; traditional oil impregnated paper, cross-linked polyethylene (XLPE) or ethylene propylene rubber (EPR). XLPE and EPR have better mechanical/dielectric characteristics than oil-paper and are hence mostly used.

3. Screen: A semi-conducting layer of paper/extruded polymer around the core to minimise electric field strength and avoid field concentration zones.

4. Sheath: Around the core a metallic sheath is applied as a water barrier and to protect the cable against fault currents.

5. Armature: The entire cable is surrounded with a metallic armature (usually galvanised steel wires) to provide the necessary mechanical strength and impact protection.

6. Optic fibre: Numerous fibre optic cables may be used for data transmission and monitoring purposes.

7. Protecting sheath: The outer layer consists of polypropylene for abrasion resistance

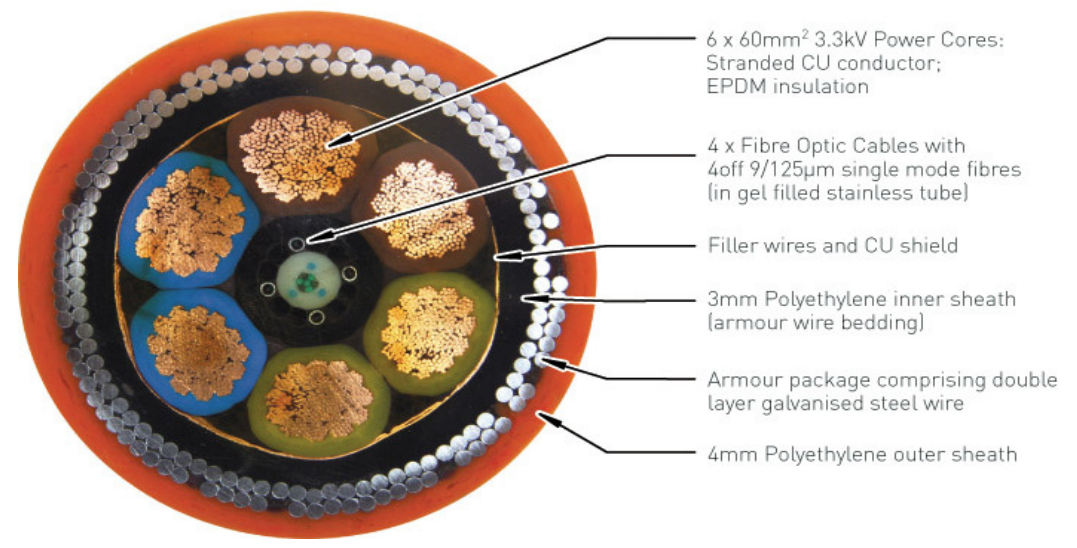

Figure 1: Example of HVAC (3.3kV) subsea power umbilical (courtesy of JDR [8]) 
The listed cable layers are combined in a cylindrical and/or helical configuration with varying diameters and differing cross-sectional designs which results in complex mechanical behaviour. It is further important to note that manufactures usually tailor-make submarine cables to the application at hand, i.e. there is no standardised cable.

The subsea geometry of the cable can vary depending on the water depth and loading regimes [9]. Some standard configurations are shown in Figure 2. The two configurations that are investigated in this paper are the simple free hanging (so-called catenary) shape and the lazy wave shape where the cable is supported with buoyancy floats to create a long radius curve in order to absorb the top-end motion (see also Figure 7).

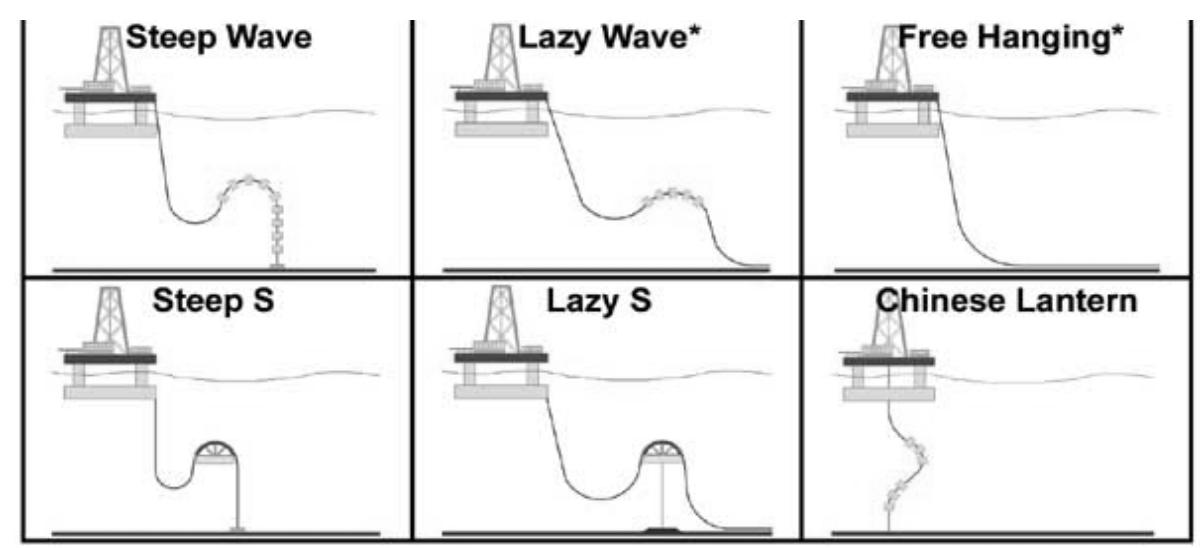

Figure 2: Standard flexible riser configurations for floating offshore structures [9]

\section{Reliability assessment for marine power cables}

A number of failure modes have been reported for marine power cables, ranging from material degradation to fatigue failure. The Umbilical Manufacturers' Federation [10] assessed failures of control umbilicals for a five year period (1995 - 2000). From a total of 21 incidents the majority (17 failures) occurred during installation/commissioning and almost half the failures were ascribed to manufacturing and installation errors. Most mechanical failures were encountered at the attachment/hang-off points. 
Patel [11] summarises the outcomes of a reliability study of electrical cables in umbilicals. The study comprised a total of 62 failures, where almost $50 \%$ of failures were caused by incorrect installation/loadout, followed by electrical faults, incorrect operation or design flaws. Other named causes were fatigue failures, poor manufacturing, marine life and accidents.

Although these studies highlight the importance of careful installation of power cables, they also emphasises the fact that mechanical failures do occur if important load parameters are neglected in the design process. Table 1 lists a number of mechanical failure modes for marine power cables and assesses their significance for marine energy applications. Three mechanical failure modes are likely to be of concern for cables connected to floating wave energy converters and it is these modes that will be further assessed:

- Exceedance of axial tension limits,

- Over bending of the power cable,

- Degradation/fatigue under extreme dynamic and cyclic loading.

\begin{tabular}{ll}
\hline Mechanical failure modes & Applicability to marine energy converters \\
\hline Severe axial tension or torque & Likely for motion dependent devices \\
Over bending & Likely at attachment points and buoyancy intersection \\
Crushing due to extreme external pressure & Not likely due to moderate water depth \\
Hose/tube bursting by excessive internal pressure & Not applicable for pure power cables \\
Layer separation and instability & Possible \\
'Birdcaging' caused by sudden tension release, & Possible if umbilical under compression (e.g. at the \\
spreading wire strands & touchdown point) \\
Loop formation and kinking & Possible \\
Mechanical degradation (wear and fatigue) & Will be important for motion dependent devices
\end{tabular}

Table 1: Mechanical failure modes of umbilicals (after Patel [11]) and applicability to marine energy converters

It is a challenging task to assess the reliability of components in an unknown application and ideally prototype deployments are required to gain field experience. In the case of marine installations field failures are very costly as they involve offshore interventions. As a result one would like to assess the reliability and identify potential failure modes prior to field 
deployment. This paper applies a combined approach to estimate the environmental load conditions of components in the absence of field experience (Figure 3).

Based on the environmental conditions at the site, experimental tests can be conducted to reproduce the most pertinent sea states to determine the motion response of the device. Subsequent numerical simulation using the measured device motions is used to calculate the load conditions for the component. The numerical results form the basis for a reliability assessment comprising both extreme load conditions and the estimation of fatigue life.

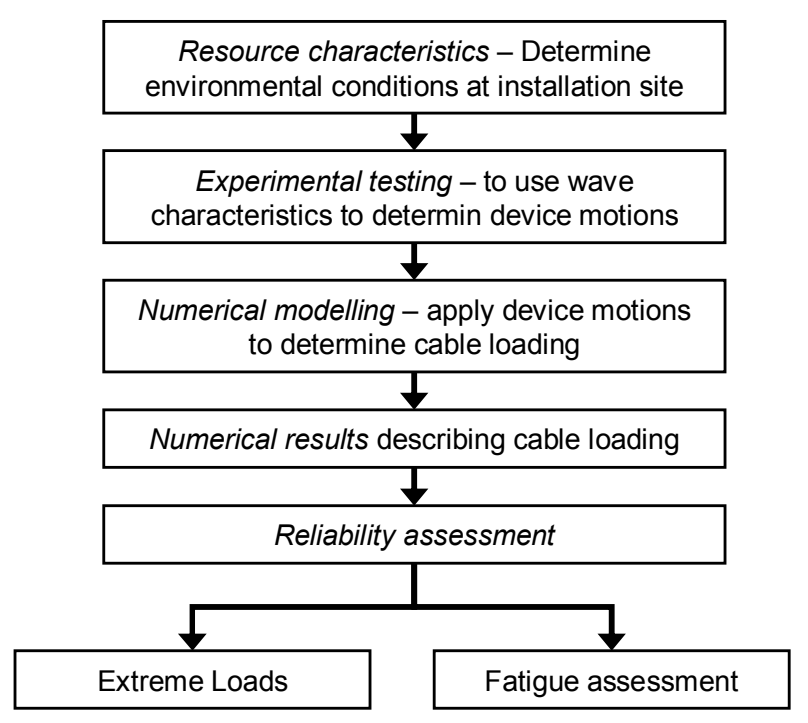

Figure 3: Methodology to assess component reliability in marine environment

The case study presented in the following aims to assess the loading regime, and produce a reliability assessment for a dynamic power cable attached to a "notional" wave energy converter when it would be installed at the Wave Hub site in South West England. The Wave Hub is a grid-connected large-scale test facility for offshore wave energy converters, located $16 \mathrm{~km}$ offshore in a water depth between 44-60m Chart Datum [12]. The wave conditions at this site are reported in a hindcast database [13] and for measurements undertaken at the site [14]. Typical wave characteristics for this site are shown in Figure 4, which also indicates the range of irregular seastates modelled in this paper $(\mathrm{Hs}=2-4 \mathrm{~m} ; \mathrm{Te}=7-9 \mathrm{~s})^{2}$. The modelled

\footnotetext{
${ }^{2}$ The significant wave height Hs describes the average height of the highest one-third of waves. The energy period Te represents the mean wave period related to the spectral distribution of the wave energy transport, i.e. Te is the period of a sinusoid of the given amplitude that has the same power as the entire spectrum.
} 
conditions occur for $21.3 \%$ [14] and $10.2 \%$ [13] of the year depending on the source (Table 2).

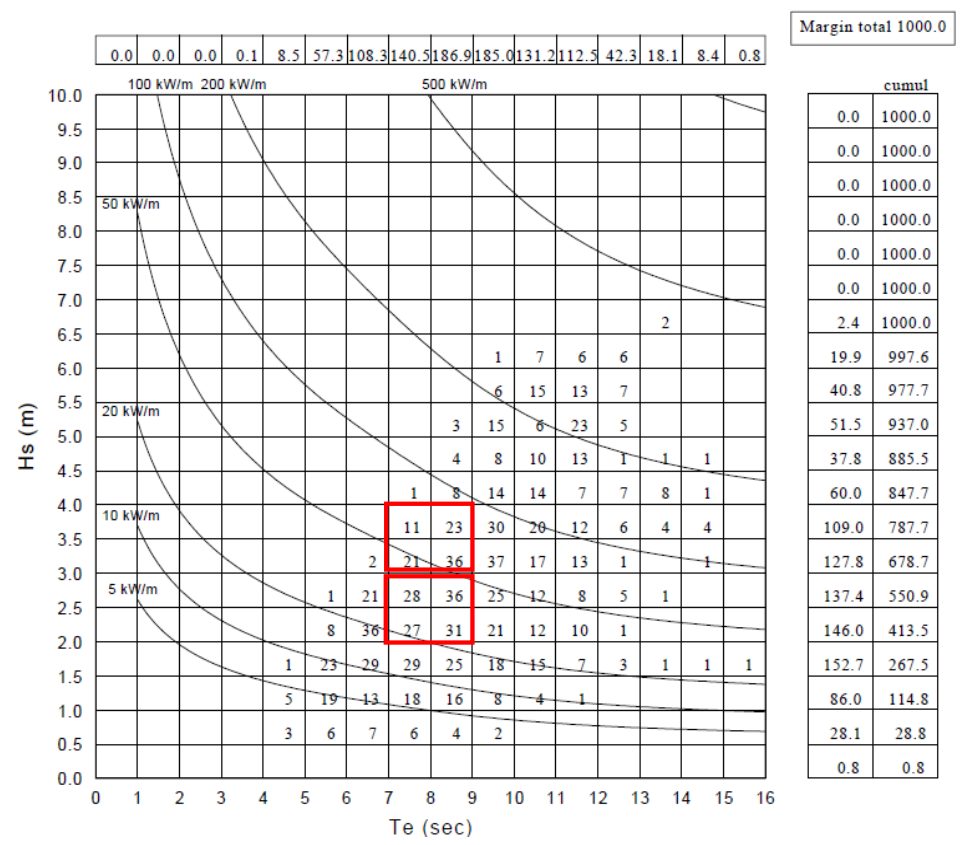

Figure 4: Wave climate characteristics at the Wave Hub site (adapted from [14])

\begin{tabular}{ll|llll|}
\multicolumn{2}{c|}{ Sea state } & \multicolumn{4}{|c}{ Estimated annual occurrence } \\
\cline { 1 - 3 } Hs [m] & T [s] & Hs [m] & Te [s] & $\begin{array}{l}\text { Occurrence [\%] } \\
{[13]}\end{array}$ & {$[14]$} \\
\hline 3.5 & 8 & $3-4$ & $7-9$ & 3.1 & 9.1 \\
2.5 & 8 & $2-3$ & $7-9$ & 7.1 & 12.2 \\
& & $2-4$ & $7-9$ & $\Sigma 10.2$ & $\Sigma 21.3$
\end{tabular}

Table 2: Annual occurrence probability of modelled seastates

Due to the limitations of available information regarding the extent of experiments and constraints in the numerical modelling of the cable cross-section this case study has been based on simplifications such as:

- simplified power cable design, i.e. cable modelled as cylinder of uniform material

- the response and load behaviour have been determined for only a limited number of seastates,

- the numerical model does not allow a coupled assessment of the floater/cable,

- no fluid loading by waves and currents is applied to the cable 
It is inherent that these simplifications will affect the specific outcomes of the reliability assessment however the general method can be easily adapted to more detailed analysis and will provide some valuable general conclusions. The research group is in the process of collecting the more detailed information required to enhance the reliability studies, which will be part of future work.

\section{Determining response and load behaviour}

Ideally, load data for an umbilical should be from measured field conditions. Such measurements have been conducted by the Foinaven Umbilical Monitoring System that recorded curvature and environmental data of an oil and gas production umbilical to assess the causes of potential fatigue damage [15]. Wave action is the main contributing factor to fatigue damage followed by mooring response and vortex induced vibration (VIV). Similar measurements are currently not available for floating MECs and load estimates are often based on tank tests and/or computational modelling [16].

The procedure applied for this paper to estimate the loading regime comprises two sequential steps:

1. Experimental tank testing to determine the motion response of the moored wave device for the representative sea states;

2. Application of the simplified numerical model based on the motion response to derive tension forces and bending radius

\subsection{Experimental tests}

The tank tests were conducted at the MARINTEK Institute (Trondheim, Norway) with the objective to study the interaction of floating wave energy devices moored in an array for a number of typical, operational sea states. The devices are at $1 / 20$ scale and are of the oscillating water column type (OWC). The operating principle for this kind of device relies on 
the wave motion displacing the air in a chamber which is open below the water surface. The alternating airflow is then used to drive a turbine (see e.g. [17] for a more detailed description). Figure 5 shows the experimental setup of one of the devices and the measurement instrumentation including mooring line load cells, optical motion tracker and accelerometers. A range of wave and current test conditions were applied while device motion and mooring forces were monitored [18]. No umbilical cable was attached during these experiments.
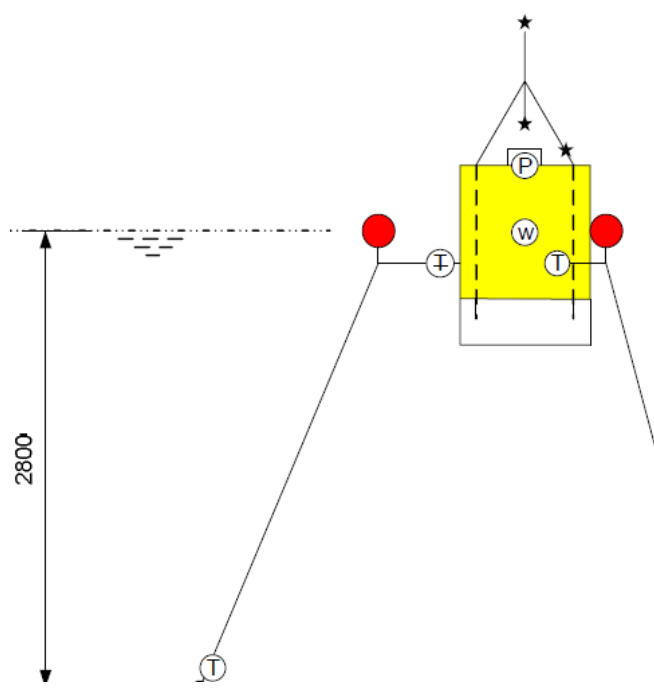

\begin{tabular}{|c|c|c|}
\hline ITEM & QTY. & DESCRIPTION \\
\hline$T$ & 6 & Tension Load Cell (200N) \\
\hline$\mp$ & 1 & Mooring line angle sensor \\
\hline P & 1 & Differential pressure transducer \\
\hline w & 1 & Internal water level sensor \\
\hline$*$ & 5 & I-R Reflectors \\
\hline$\bullet$ & 3 & Fixed mooring point \\
\hline
\end{tabular}

Figure 5: Experimental setup and mooring dimensions [mm] of generic floating OWC. Left elevated view; Right - instrumentation and plan view.

A total of 12 different sea states (regular and irregular) have been simulated in the experiments varying both significant wave height $\mathrm{Hs}$ and wave period $\mathrm{T}$ covering a full-scale range from $\mathrm{Hs}=2-6 \mathrm{~m}$ and $\mathrm{T}=5-13$ seconds. The high sample frequency for data acquisition, $f=20 \mathrm{~Hz}$, was adopted to enable the measurement of the dynamic movements and loads. All data shown in the following has been upscaled using Froude's scaling law [19]. 
Figure 6 shows a 30s sample recorded during a test with irregular waves; Hs $=3.5 \mathrm{~m}$, $\mathrm{T}=8.0 \mathrm{~s}$. The translational and rotational response for each motion axis is depicted against the measured wave elevation. The vertical displacement (heave) and rotation of the $x$-axis (pitch) constitute the main responses of the device, which is to be expected, as the device approximately follows the wave elevation and the $\mathrm{x}$-axis was defined perpendicular to the incoming wavefront.

The measured motions are used as input to the computational model (section 4.2) to define the motion of the floating wave energy converter connected to a dynamic power cable. The assumption made for the model is that the umbilical itself does not significantly alter the motion of the floating device. Given that the mass of the device is much larger than that of the umbilical cable, this is considered a reasonable assumption.
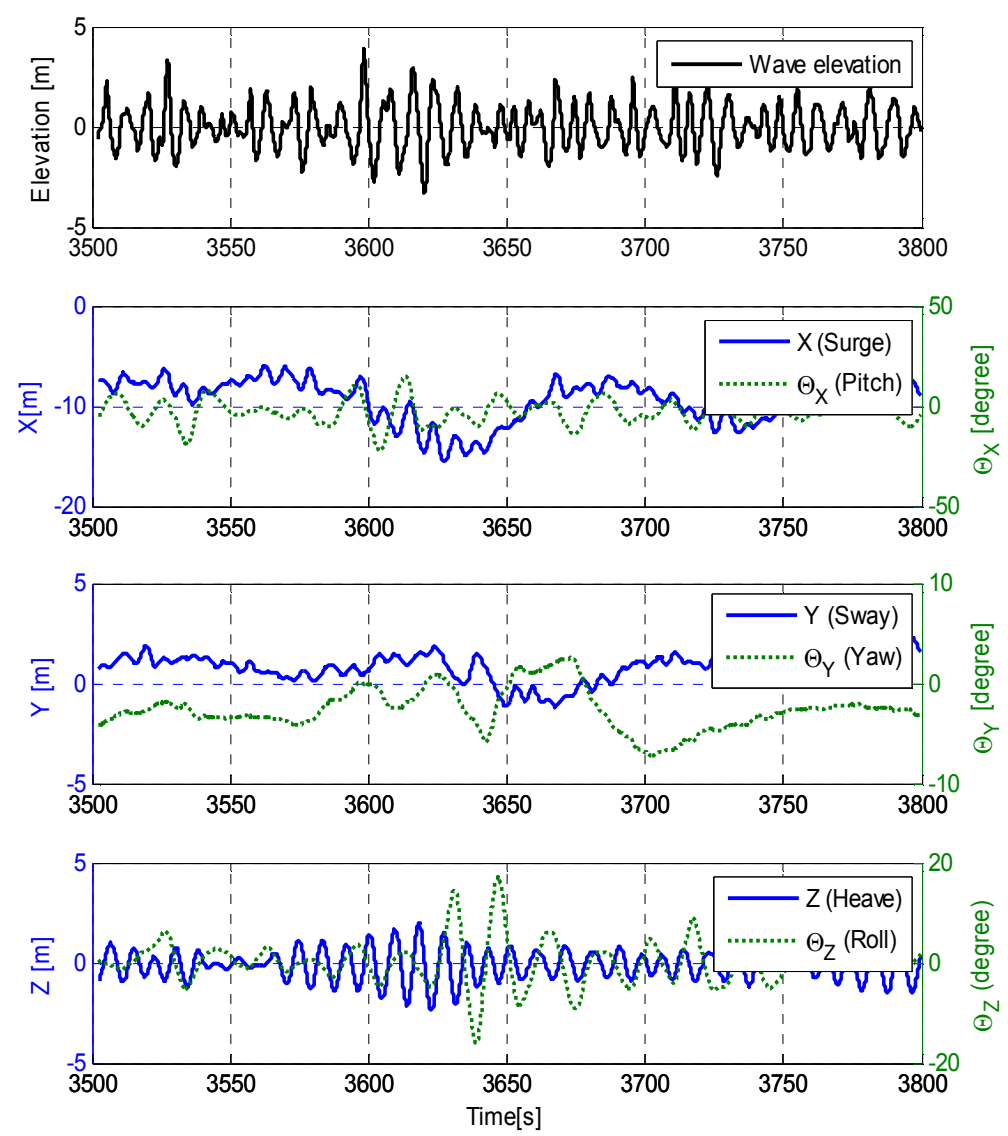
Figure 6: Sample section for six degree of freedom motion response. Top - wave elevation.

Three lower plots - translational/rotational displacement for each axis. Left ordinate translational movements $(X, Y, Z)$; Right ordinate - Rotational movements $\left(\theta_{X}, \theta_{Y}, \theta_{Z}\right)$.

\subsection{Computational model}

Marine cable dynamics can be modelled with a number of different approaches. Analytical methods as presented in $[20,1]$ simplify the system and estimate the parameters of interest, e.g. maximum tension force or system stability.

For this paper the proprietary marine dynamics software OrcaFlex ${ }^{\circledR}$ from Orcina has been used to estimate the loadings on the umbilical. The software is a three-dimensional non-linear time domain finite element program which employs a lumped mass element approach to solve the dynamic behaviour of line objects, i.e. sections of the cable [21].

The umbilical/cable is represented as a series of segments with a node at each end. While the segments carry the axial and torsional characteristics, all other properties (mass, weight, buoyancy etc.) are lumped into the nodes. Forces and moments are applied at the nodes, while the segments are treated as straight massless elements with axial- and torsional springdamping characteristics. The end of each segment additionally carries a rotational springdamping term that models the bending characteristics.

The computational model has been set up, comprising the following elements:

- The OWC device modelled with translational and rotational movements;

- The marine power cable (with two separate geometries)

- An attachment point at the bottom centre of the OWC device, modelled as flexible joint with three rotational degrees of freedom.

- An, anchor point on the seabed 
The power umbilical has been modelled as a double armoured power cable in two configurations i) catenary and ii) lazy wave (Figure 7). To achieve the lazy wave shape additional floats have been attached around the cable. The double armour configuration provides the tension stability and mechanical protection. The total cable length of $120 \mathrm{~m}$ (catenary) and $130 \mathrm{~m}$ (lazy wave) in a water depth of $57 \mathrm{~m}$ are chosen corresponding to the Wave Hub installation site. The properties of the umbilical and buoyancy sections are given in Table 3.

\begin{tabular}{lccc}
\hline \multicolumn{1}{c}{ Name } & Unit & 2-Armoured cable & Buoyancy section \\
\hline Total length & $\mathrm{m}$ & 50 (section 1) & 40 (section 2) \\
\hline Outside diameter & $\mathrm{mm}$ & 200 & \\
Nominal weight in air & $\mathrm{N} / \mathrm{m}$ & 706 & 306 \\
Nominal weight in seawater & $\mathrm{N} / \mathrm{m}$ & 390 & 423 \\
Bending stiffness & $\mathrm{kN} \cdot \mathrm{m}^{2}$ & 10 & -316 \\
Axial stiffness & $\mathrm{MN}$ & 700 & 10 \\
Torsional stiffness & $\mathrm{kN} \cdot \mathrm{m}^{2} / \mathrm{deg}$ & 600 & 700 \\
Minimum Breaking Load & $\mathrm{kN}$ & 100 & 600 \\
Minimum bend radius (MBR) & $\mathrm{m}$ & 2 & 100 \\
Connection stiffness & $\mathrm{kN} \cdot \mathrm{m} / \mathrm{deg}$ & X-bend: 10 & 2 \\
& & $\mathrm{y}$-bend: stiff & X-bend: 10
\end{tabular}

Table 3: Characterisation data for modelled umbilical (armoured cable properties after [16]; connection stiffness [22])

The simulation considers all geometric non-linearities as the system geometry is recomputed at every time step. The integration time step was set to $0.02 \mathrm{~s}$, which is sufficiently small to capture high frequency responses. The tension forces are computed first, followed by the bend moment, shear forces, torsion moment and the total load. 

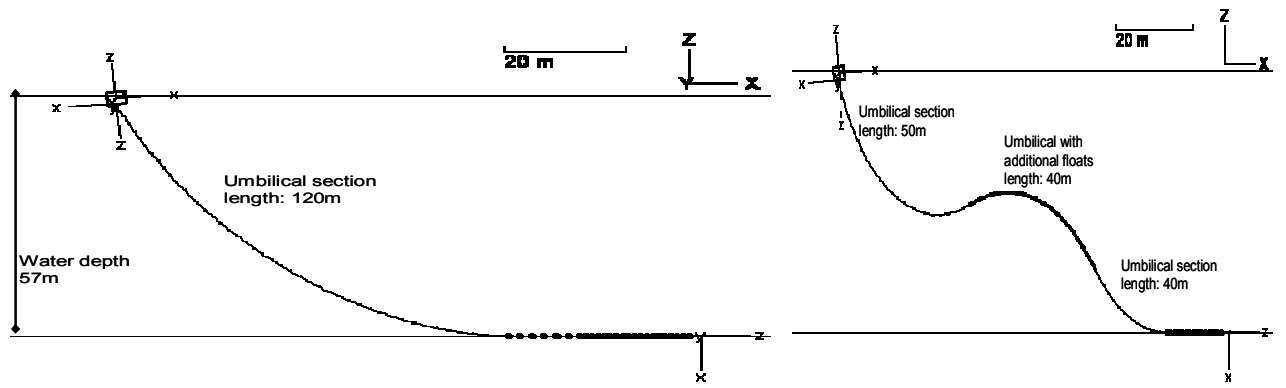

Figure 7: Orcaflex model of armoured umbilical in catenary (left) and lazy wave configuration (right) attached to buoy having six degrees of freedom

\subsection{Results of response and load behaviour}

The results of the dynamic simulation are presented with regard to four main aspects:

i. A determination of the points of maximum loading

ii. Computation of the tension force and bend radius near the attachment point

iii. An analysis of the cyclic loading near attachment point

iv. An investigation of the Influence of varying wave parameters

\subsubsection{Points of maximum loading}

The maximum load conditions are assessed for one irregular sea state with a significant wave height $\mathrm{Hs}=3.5 \mathrm{~m}$ and a wave period of $\mathrm{T}=8 \mathrm{~s}$, which was repetitive of the range of sea states. The sensitivity of load conditions is discussed for regular and irregular sea states with $\mathrm{Hs}=2-6 \mathrm{~m}$ and $\mathrm{T}=5-13 \mathrm{~s}$ in section 4.3.4.

The points of maximum loading along the umbilical are identified in Figure 8. This shows the maximum, mean and minimum tension force along the entire umbilical for both configurations. The catenary shape exceeds the allowable tension of $100 \mathrm{kN}$ at the attachment point and experiences compression loads (negative tension values), in particular at the touchdown point. 
In the case of the lazy wave configuration, the highest forces occur near the attachment point and at the transition points of the buoyancy section. In the following, the focus will be on the load conditions near the attachment point.
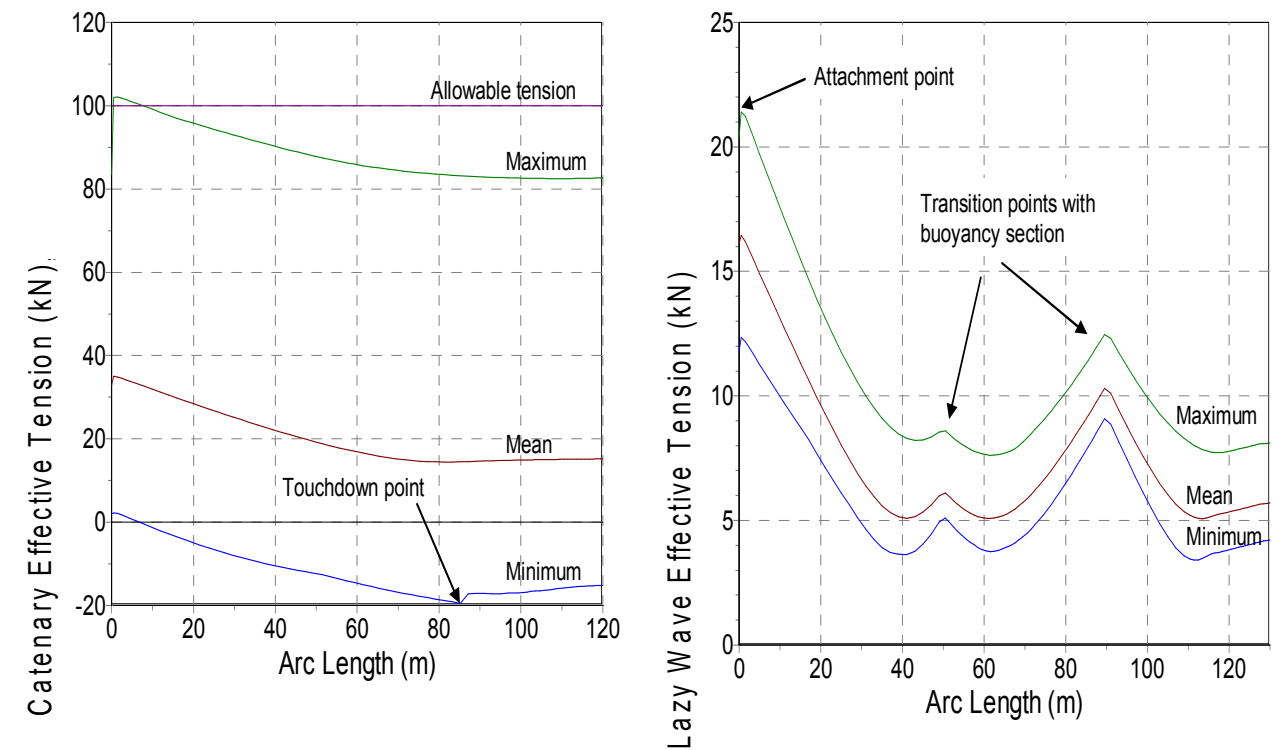

Figure 8: Minimum, mean and maximum tension (compression) along the length of the umbilical $(\mathrm{Hs}=3.5 \mathrm{~m}, \mathrm{~T}=8 \mathrm{~s})$ Left - catenary; right - lazy wave configuration

\subsubsection{Tension force and bend radius near the attachment point}

Figure 9 shows the time series of tension forces near the attachment point resulting from the wave energy converter motions described in section 4.1, Figure 6 . Although both umbilical configurations are subject to the same imposed movements of the floating body the resulting forces are quite different. While in the catenary case the motion response of the floater leads to high peak tension forces $(>100 \mathrm{kN})$, the compliant design of the lazy wave shape absorbs the movements and exhibits only a moderate increase of tension forces $(<22 \mathrm{kN})$ above that in the static condition. 

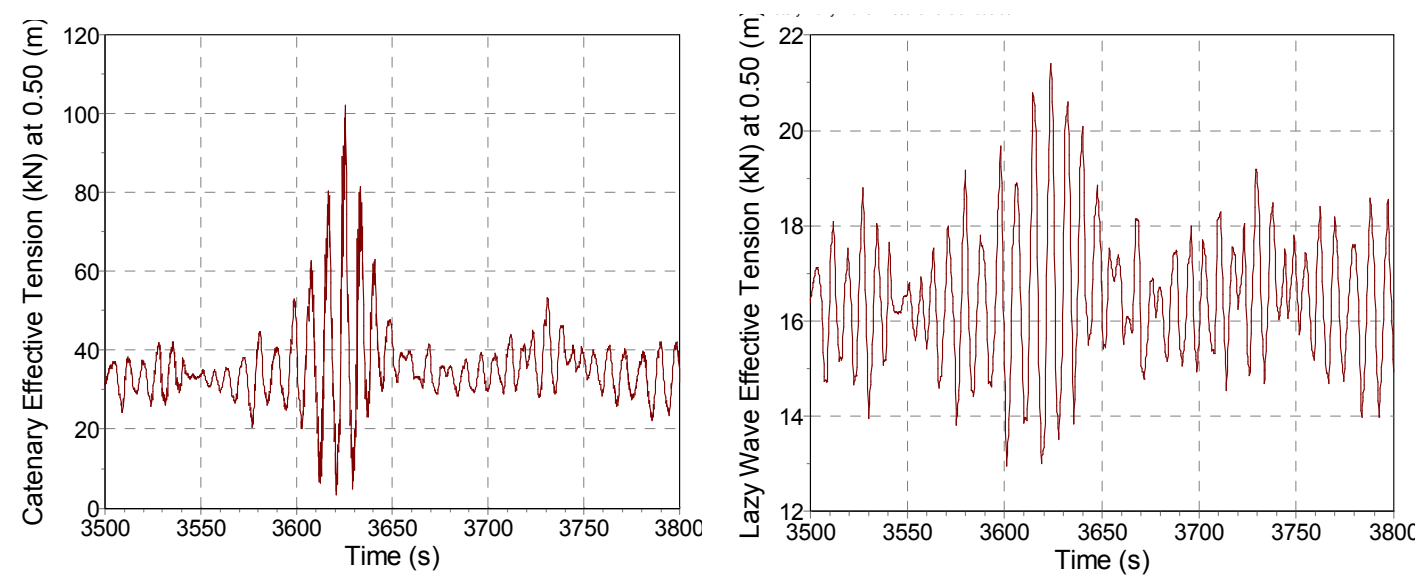

Figure 9: Time series of the effective tension $0.5 \mathrm{~m}$ off the attachment point. Left - catenary; right - lazy wave configuration. N.B. different scales of $y$-axis

The largest bending moments near the attachment point are just under $6 \mathrm{kN}$ (catenary) and $4 \mathrm{kN}$ (lazy wave). The bending moment correlates to a bending radius which is typically being used as design parameter. For the modelled cable the minimum bend radius is given as $M B R=2 m$ [16], i.e. the bend radius must not be smaller in order not to damage the cable. The bend radius falls below the critical value of $2 \mathrm{~m}$ for the catenary shape $(1.7 \mathrm{~m})$ but remains above it for the lazy wave shape $(2.5 \mathrm{~m})$.

\subsubsection{Cyclic loading near attachment point}

The time series presented illustrate that the power cable is subject to considerable cyclic load conditions. A common method to quantify the cyclic pattern and evaluate the fatigue damage of load signals is the rainflow count. This method identifies and counts the stress range corresponding to individual hysteresis loops [23].

The counted rainflow half cycles of the device's motion response and the power cable's load cycles are listed in Table 4Error! Reference source not found.. The motion response cycles are reported for each degree of freedom while the load cycles are distinguished by load type (tension/bending) and by cable configuration (catenary/lazy wave). The comparison shows that the computed load cycles are more numerous than would be expected from solely considering any of the motion responses in a single degree of freedom (DOF) approach. This is the case for both tensional forces and bending moments. For example, the heave motion 
response of the device amounts to about 1,800 half cycles, while there are more than twice as many tension- and bend moment half cycles. Thus all 6 DOFs must be considered in the design analysis, which is the case for the coupled computational analysis.

\begin{tabular}{ll|l|cc}
\hline \multicolumn{2}{c|}{ Motion response of device } & \multicolumn{2}{c}{ Load cycles (0.5m off attachment point) } \\
\hline Surge $(\mathrm{X})$ & 2,214 & Configuration & Catenary & Lazy-Wave \\
\cline { 3 - 3 } Sway $(Y)$ & 2,275 & Tension force cycles & 3,846 & 3,124 \\
Heave $(Z)$ & 1,856 & Bend moment cycles & 3,603 & 2,677 \\
Pitch $\left(\theta_{X}\right)$ & 1,198 & & \\
Yaw $\left(\theta_{Y}\right)$ & 1,480 & & \\
Roll $\left(\theta_{Z}\right)$ & 1,262 & &
\end{tabular}

Table 4: Rainflow halfcycles for motion response of the device and umbilical tension/bending cycles near attachment point. Length of the simulation is $135 \mathrm{~min}$; irregular waves with $\mathrm{Hs}=3.5 \mathrm{~m}, \mathrm{~T}=8 \mathrm{~s}$.

\subsubsection{Influence of wave parameters}

The analysis so far has been concerned with the irregular sea state with the largest motion response of the device. To assess the load conditions for varying operating environments different wave states must be considered. In the following the sensitivity of maximum loads and fatigue cycles is shown with respect to significant wave height and wave period for regular and irregular sea states.

\section{Wave height}

As can be expected, an increase in wave height leads to an increased maximum tension force near the attachment point (see Figure 10). The largest tensional force in case of the lazy wave shape is $F_{\max , \text { Lazy }}=23.4 \mathrm{kN}$ for $\mathrm{Hs}=6 \mathrm{~m}$.

For the catenary configuration the maximum tensional force also occurred for the largest wave height $(\mathrm{Hs}=6 \mathrm{~m})$ giving $F_{\max , \text { Catenary }}=140.9 \mathrm{kN}$.

The lazy wave configuration exhibits a lower maximum tension forces in comparison with the catenary configuration for all simulated sea states. In fact a threefold increase of Hs leads to a 
$1 / 3$ increase of maximum loads for the lazy wave shape compared to a 4 fold increase for the catenary case. Indeed, the lazy wave configuration reduces the maximum tension force up to a factor of 6 for the modelled conditions.

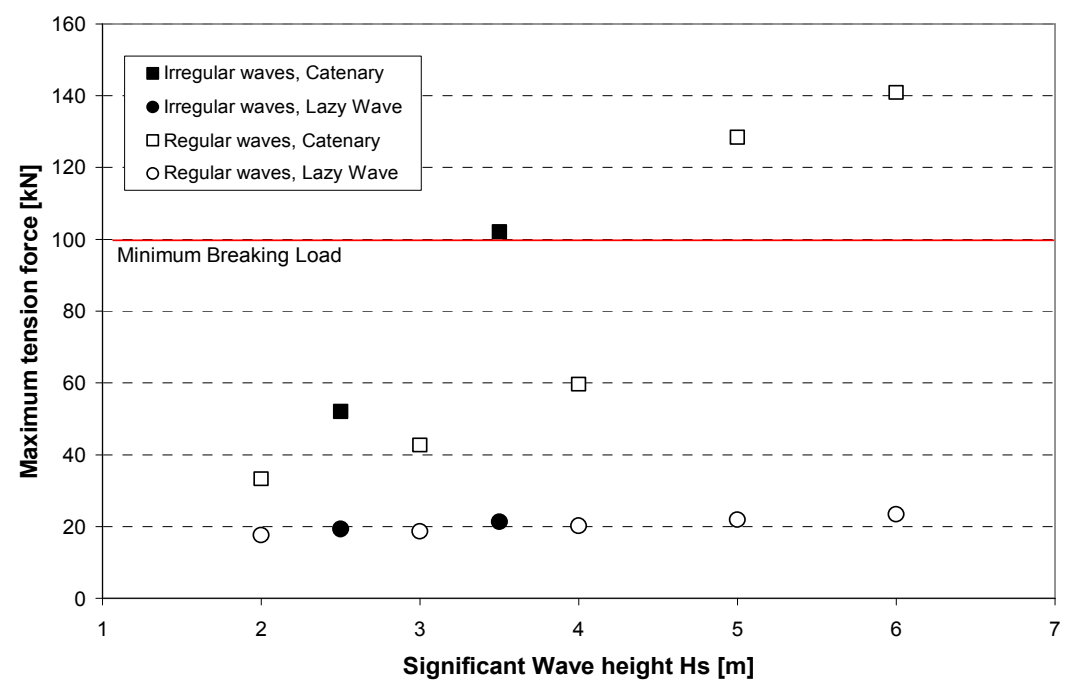

Figure 10: Maximum tension forces ( $0.5 \mathrm{~m}$ off attachment point) for different wave heights and cable configurations

Similarly increasing wave heights lead to higher bending moments which in turn is reflected in a reduction of bending radii of the power cable (Figure 11). It can be further seen that the minimum bending radius decreases in the more realistic irregular sea states for the catenary shape, i.e. the cable is subjected to larger bending moments in irregular seas.

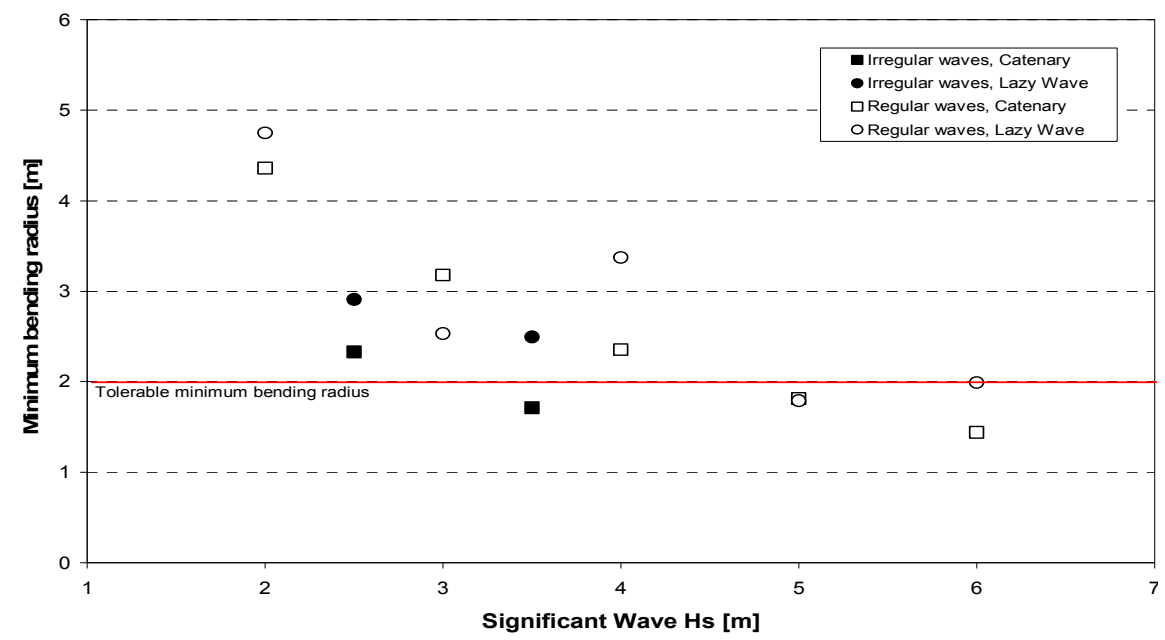

Figure 11: Minimum bending radius ( $0.5 \mathrm{~m}$ off attachment point) for different wave heights 
While the device motion response for different wave heights influences the load amplitude, it does not have a considerably effect on the number of load cycles. For a modelled $25 \mathrm{~min}$ period about 500 (600) half cycles are counted for the tension force in regular (irregular) sea states. There are slightly less bending half cycles of approximately $400(500)$ in regular (irregular) seas.

\section{Wave period}

The wave period has a direct effect on the number of load cycles. Figure 12 shows the counted half cycles for both tension forces and bending moments for different wave periods. An increasing wave period reduces the number of load cycles, as the motion response frequency of the device is governed by the incident wave period. An increase of wave period from $5 \mathrm{~s}$ to $13 \mathrm{~s}$ reduces the number of counted load cycles by about a factor of 2 . The resonance effects at $9 \mathrm{~s}$ (half of the device natural frequency) can be seen in the pronounced drop in load cycles, as larger amplitude, lower frequency oscillations dominate he motion response. Tensional load cycles tend to be more numerous than bending moment cycles.

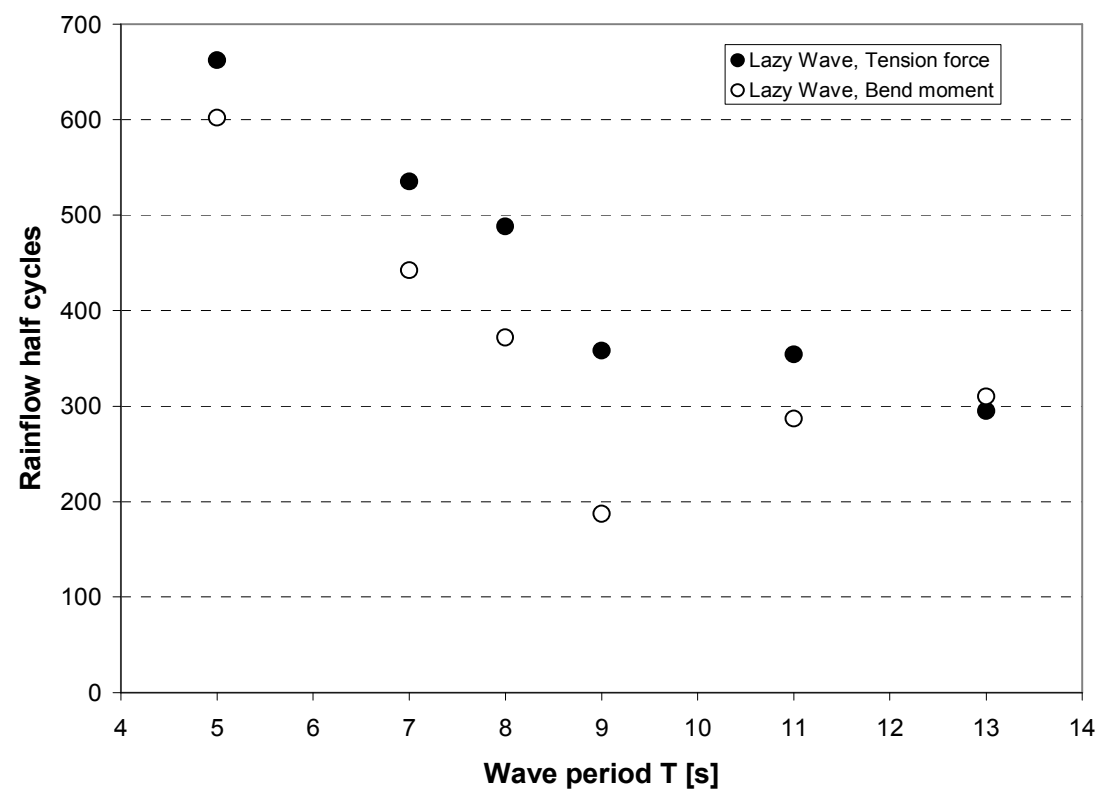

Figure 12: Rainflow half cycles of lazy wave configuration for different wave periods (regular sea states, $\mathrm{Hs}=2 \mathrm{~m}$, calculated $0.5 \mathrm{~m}$ off attachment point, duration of $25 \mathrm{~min}$ ). 


\section{Reliability assessment}

The performance assessment of a system regarding reliability, availability and maintainability (RAM) provides crucial information for decisions on project investment, design alternatives, and maintenance strategies and the identification of necessary improvements. Two general approaches can be distinguished, measurement-based techniques and model-based assessments [24]. The approach applied here is a combination of both, using experimental measurements and numerical modelling tools to assess the reliability of the marine cable in the marine application. Two reliability aspects are considered:

1. Compliance of maximum loads with limiting design specifications

2. Estimation of fatigue life for cable copper conductor

\subsection{Maximum load assessment}

Two mechanical design specifications of the power cable that must not be exceeded to ensure the integrity of the cable are considered here. The minimum breaking load (MBL) is given at $M B L=100 \mathrm{kN}$ while the minimum bend radius $(M B R)$ is specified as $M B R=2 m[16]$.

Figure 10 shows the maximum tension forces for the catenary and lazy wave configuration in a number of seastates. The free hanging catenary cable exceeds the MBL in a number of cases by up $40 \%$ of the MBL in the most extreme case of $\mathrm{Hs}=6 \mathrm{~m}$. The lazy wave shape does not exceed the cable strength in any of the modelled sea states. In fact, the forces are reduced and compression is avoided in comparison to the catenary shape. However, this introduces two load peaks at the buoyancy transition points (Figure 8). This is consistent with the guidelines given in [25] for compliant riser systems which indentify the area in the wave zone, hog- and sag bends and terminations as the most critical, failure-prone locations.

High peak tensions in dynamic applications can be avoided with a lazy wave configuration, while the catenary is subject to severe peak loads induced by the dynamic motion response of the floating wave device. Moreover, comparing regular and irregular wave conditions the results indicate that the lazy wave design does not suffer from significant load increases in irregular waves, as it is the case for the catenary geometry. 
The bending radius the cable is subjected to in different sea states is plotted in Figure 11.

With a MBR of $2 m$ it can be seen that the cable has the potential to suffer damage for wave heights larger than $4 \mathrm{~m}$ for both the catenary and umbilical configuration. As wave energy converters will be typically deployed in more energetic sea conditions this strongly indicates the requirement for a bend stiffener to restrict the bending and avoid kinking/damaging the cable near the attachment point. Bend stiffeners require careful design and are specifically tailored to the predicted load cases [26].

The comparison of regular and irregular seastates in Figure 11 shows more extreme bending radii for the catenary shape in realistic, irregular seas. This may indicate that the lazy wave configuration might be more suitable in field conditions.

\subsection{Fatigue life estimation}

The initial analysis of load cycles indicated that a large number of load cycles (in the order of $10^{6}$ ) may occur during a year of operation, due to the highly cyclic load characteristic. Therefore a more detailed fatigue assessment was carried out for the copper conductor of the lazy wave umbilical configuration. Electrolytic Tough Pitch (ETP) copper is most commonly used for power conductors [27] and is assumed as conducting material in the following.

The fatigue life estimation is performed in three sequential steps. Firstly, the number of strain cycles is counted for the modelled seastates. Secondly, the accumulated cycles are estimated for the load characteristics representative of those at the Wave Hub site. Finally, the fatigue limit is assessed through material fatigue curves.

\subsubsection{Stress-cycle $(\mathrm{S}-\mathrm{N})$ and Strain-cycle $(\varepsilon-\mathrm{N})$ fatigue curves}

Empirically derived S-N curves are the conventional point of reference for fatigue assessments, showing the number of cycles a material can withstand until failure, depending on the stress range [23]. However, copper is characterised by non-linear stress-strain behaviour and stress relaxation. For this reason Karlsen et al. [28] propose the use of a strain-cycle $(\varepsilon-\mathrm{N})$ curve for ETP copper which accounts for both the elastic and plastic strain. 
The total strain amplitude $\varepsilon_{\mathrm{a}}$ as sum of plastic $\varepsilon_{\mathrm{a} \text {, pl }}$ and elastic strain $\varepsilon_{\mathrm{a} \text {, el }}$ can be written as Equation 5.1 (Coffin-Manson relation) [23]. The $\varepsilon-\mathrm{N}$ curve for copper is plotted in Figure 13.

$$
\varepsilon_{a, t o t a l}=\varepsilon_{a, p l}+\varepsilon_{a, e l}=C_{1} N^{-\beta_{1}}+C_{2} N^{-\beta_{2}}
$$

Where $C$ and $\beta$ are material dependent constants describing the shape of the fatigue curve, for the copper fatigue curve in Figure 13 these are: $C_{1}=0.7692 ; \beta_{1}=0.5879 ; C_{2}=0.0219 ; \beta_{2}=0.1745$.

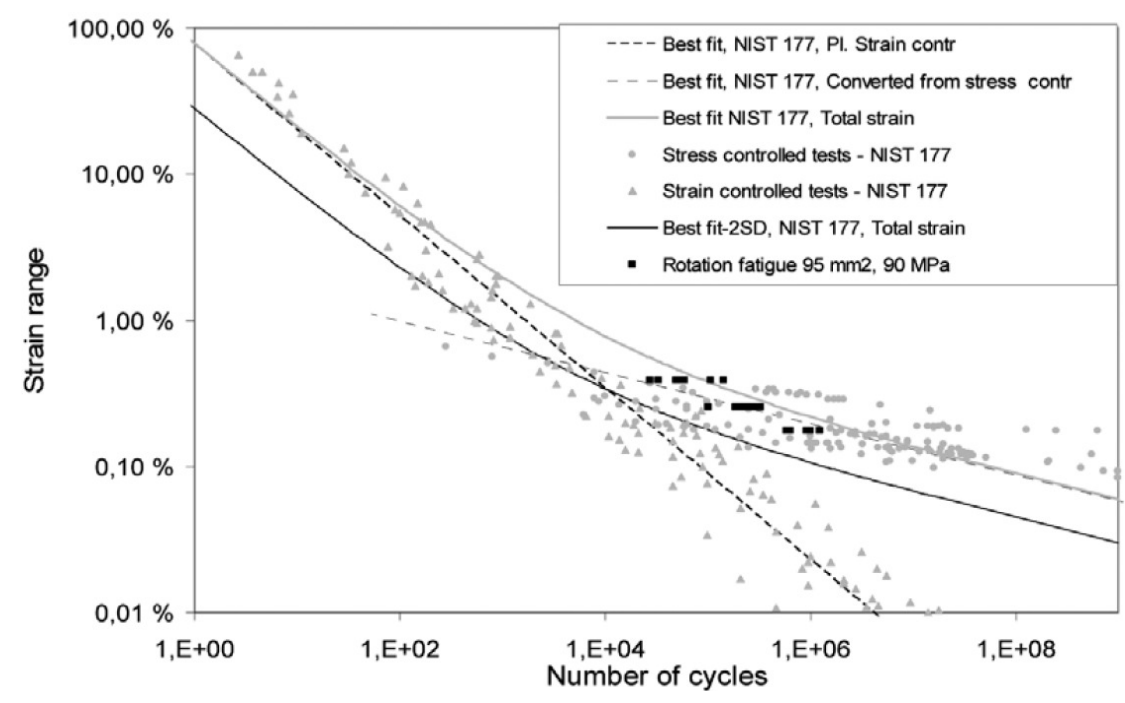

Figure 13: Strain-cycle $(\varepsilon-N)$ fatigue curve for copper conductor (reproduced from Karlsen

[28]. Graph shows results from Simon et al. [32] for different copper qualities (under stress and strain controlled conditions) and results from rotational fatigue tests by [28]

\subsubsection{Conductor strain calculation}

The maximum strain range, $z z$ is calculated as the sum of tensile and bending strain, the cable is exposed to at the outer diameter. A time series of the strain cycles near the attachment point for the outer diameter of the power cable is shown in Figure 14.

The stress/strain calculations models the cable as a cylinder of uniform material, i.e. friction stresses of different cable layers are not considered. As a consequence, the calculated stress/strain results are not directly applicable to composite structures, such as multi-layered umbilicals. [21]: There are a number of software tools available that perform the crosssectional stress analysis with more specific FEA models [30, 31]. For the purpose of this 
study though, the strain results calculated under the above assumptions will be used to estimate the fatigue life.

It is well known that the smallest load cycles do not significantly contribute to fatigue damage. Hence, it is not sufficient to solely consider the total number of cycles in estimating the damage. The stress/strain range of each cycle also has a profound impact on the resulting fatigue damage. For this analysis small strain cycles are not considered. The threshold is chosen at $1 \%$ strain, as this represents the region of elastic-plastic transition (see Figure 13). Another aspect to consider is that the conductor is located about half the diameter away from the umbilical centre (Figure 1) which means that the strain, as calculated at the outer diameter, is a very conservative estimate for the conductor. If the cable is treated as simple beam, following the Euler-Bernoulli hypothesis (i.e. plane sections stay plane), the stress can be calculated as [32] given in Equation 5.2. For a constant Young's Modulus E, the strain $\varepsilon$ experienced by the conductor is half the outside diameter strain, since ${ }_{\varepsilon}=\frac{\sigma}{E}$.

$$
\sigma=\frac{M_{x}}{I_{x}} \cdot y
$$

Where $\sigma=$ stress, $\mathrm{M}=$ moment for a given axis, $\mathrm{I}=$ second moment of area and $\mathrm{y}=$ distance from the centreline

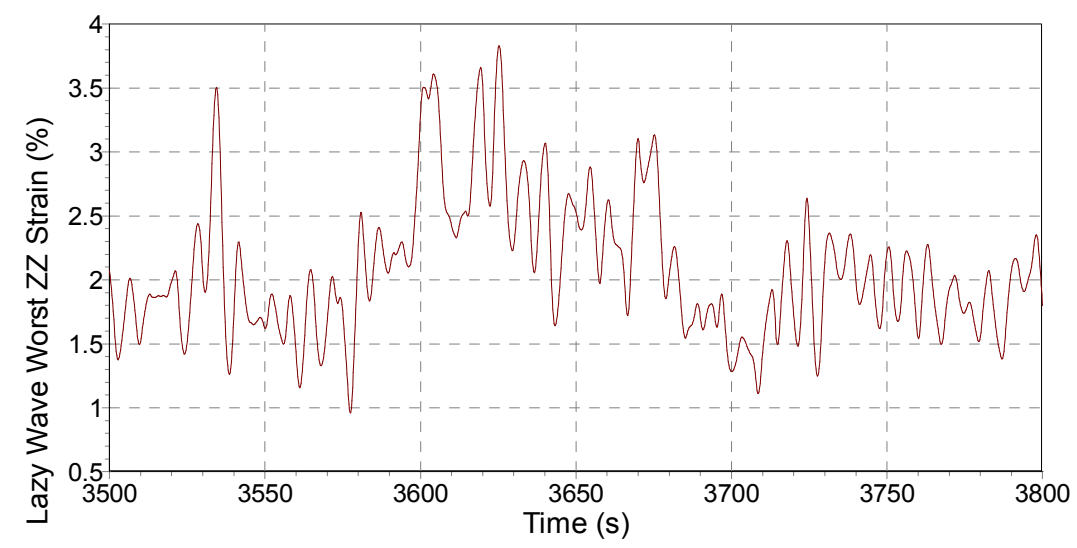

Figure 14: Umbilical strain time series (0.5m off the attachment point, for outer diameter). Worst $Z Z$ strain relates to the maximum sum of tensile and bending strain.

\subsubsection{Number of strain cycles - Rainflow cycle counting}


The rainflow cycle count was performed in Matlab using the Wafo toolbox described in [33]. The rainflow algorithm is based on the definition of Rychlik [34]. Starting from a local load maximum $\mathrm{Max}_{\mathrm{K}}$, two minima before and after $\mathrm{Max}_{\mathrm{K}}$ are identified. The minima with the smaller deviation from $\mathrm{Max}_{\mathrm{K}}$ is chosen as the rainflow minimum $\mathrm{Min}_{\mathrm{K} ; \mathrm{RFC}}$, and hence the $\mathrm{k}$ :th rainflow cycle $\left(\operatorname{Min}_{\mathrm{K} ; \mathrm{RFC}} ; \operatorname{Max}_{\mathrm{K}}\right)$ is defined.

The rainflow plots for the irregular sea states are depicted in Figure 15. The matrix shows the number of cycles that occur within each bin for a particular minimum and maximum of the strain. While at $\mathrm{Hs}=2.5 \mathrm{~m}$, three load cycles larger than the $1 \%$ strain level occur, 29 full load cycles larger than $1 \%$ strain range are counted for the conductor at $\mathrm{Hs}=3.5 \mathrm{~m}$.
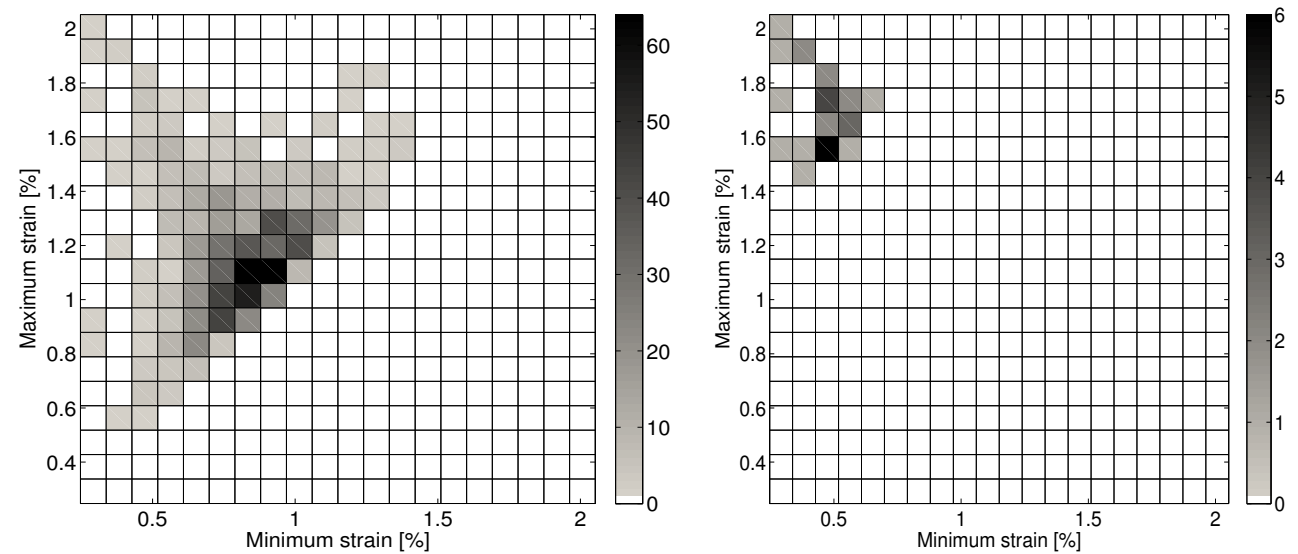

a) Rainflow cycles for irregular sea $(\mathrm{Hs}=3.5 \mathrm{~m}, \mathrm{~T}=8 \mathrm{~s})$
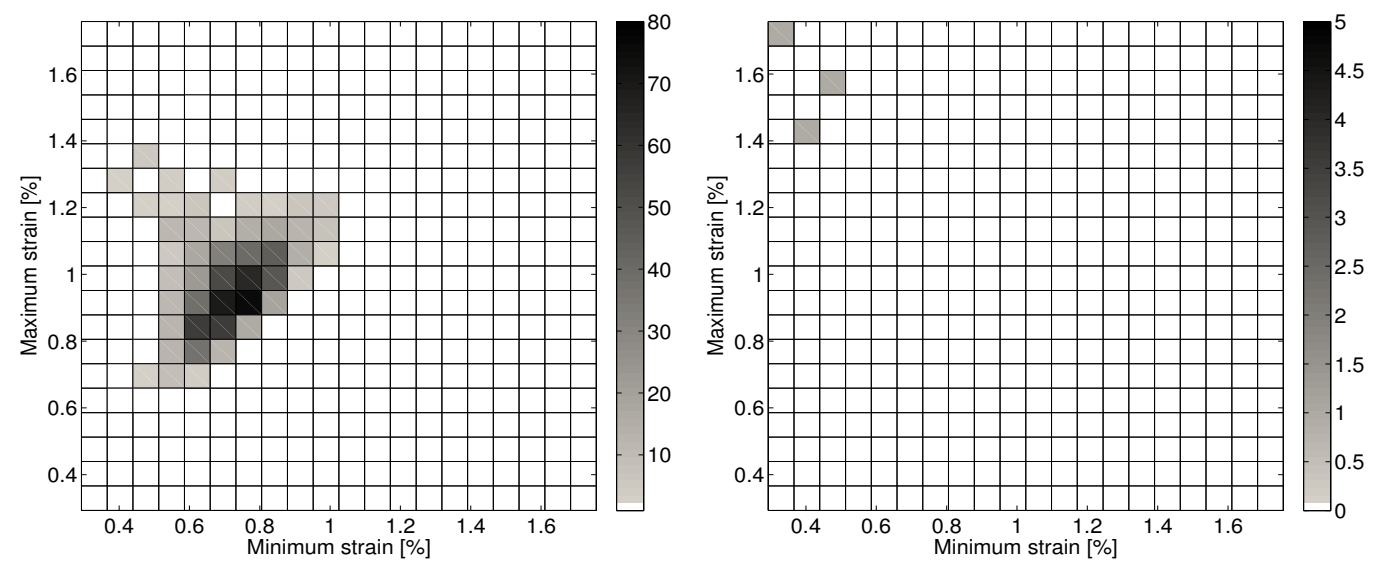

b) Rainflow cycles for irregular sea $(\mathrm{Hs}=2.5 \mathrm{~m}, \mathrm{~T}=8 \mathrm{~s})$

Figure 15: Rainflow strain cycle analysis of cable conductor strain cycles (lazy wave geometry) before (left) and after filtering with a threshold of $1 \%$ strain range (right).

\subsubsection{Estimating annual load cycles}


To estimate the number of load cycles the cable conductor would experience during a typical year of operation, the number of load cycles for each sea state are calculated for the annual occurrence probability (Table 2) of the respective sea state interval (Equation 5.4). The resulting estimated conductor strain cycles for the modelled range of sea states together with the copper fatigue limits at constant $1 \%$ strain amplitudes are given in Table 5 and are graphically presented in Figure 16.

$$
N_{\text {annual }}\left(H_{s}\right)=N_{\text {experiment }} \cdot \frac{t_{a}}{t_{\text {experiment }}} \cdot P\left(H_{s}\right)
$$

Where $\mathrm{N}_{\text {annual }}(\mathrm{Hs})=$ number of strain cycles during a typical year for a particular sea state $\mathrm{t}_{\mathrm{a}}=8760 \mathrm{~h}$,

$t_{\text {experiment }}=$ experimental time $[\mathrm{h}]$ and $\mathrm{P}(\mathrm{Hs})$ is the occurrence probability of a particular sea state

\begin{tabular}{llll}
\multicolumn{2}{c}{ Sea state } & \multicolumn{2}{c}{$\begin{array}{c}\text { Experimental tank } \\
\text { test }\end{array}$} \\
Hs & $\mathrm{T}[\mathrm{s}]$ & $\begin{array}{l}\text { Time } \\
\text { texperiment } \\
{[\mathrm{m}]}\end{array}$ & \multicolumn{1}{c}{ Cycles } \\
& & $\mathrm{N}_{\text {experiment }}$ \\
3.5 & 8 & 2.25 & 29 \\
2.5 & 8 & 2.25 & 3
\end{tabular}

Annual accumulated cycles,

calculated with calculated with seastates given seastates given in HSE [13] in Pitt [14]

$3,500 \quad 10,275$

829

$\Sigma 4,329$
1,425

$\Sigma 11,699$
Fatigue limit $\varepsilon-\mathrm{N}$ curve $1 \%$ strain range

Best fit Best fit -2SD

5,100

590

Table 5: Strain cycles (exceeding 1\% range) for copper conductor in lazy wave double armoured umbilical - experimental tests and annual accumulated cycles for seastate at Wave Hub site.

Although the results are approximations of the copper conductor strain cycles, the number of cycles clearly exceeds the conservative fatigue limits of the $\varepsilon-N$ curve at $1 \%$ strain range (Best fit - 2 standard deviations). The best-fit fatigue limit is exceeded for an annual probability of $21.3 \%$ and nearly reached for the lower estimate of $10.2 \%$ occurrence probability.

This is especially of concern as the site specific evaluations for the Wave Hub site do only constitute fractions of a year, i.e. the fatigue estimates in Table 4 are made for a maximum of $21.3 \%$ of annual seastates. 
Even though it must be noted that the actual number of cycles is device- and site specific, the results presented quantify the potential fatigue failure for a generic wave energy converter at a particular site and lead to the conclusion that the copper conductor of a typical dynamic power cable would have an unacceptable short fatigue life of less than a year. This type of fatigue estimate would not be uncharacteristic over a wider range of floating marine applications. However, fatigue failures near the attachment point are usually mitigated through the design and implementation of dedicated bend stiffeners.

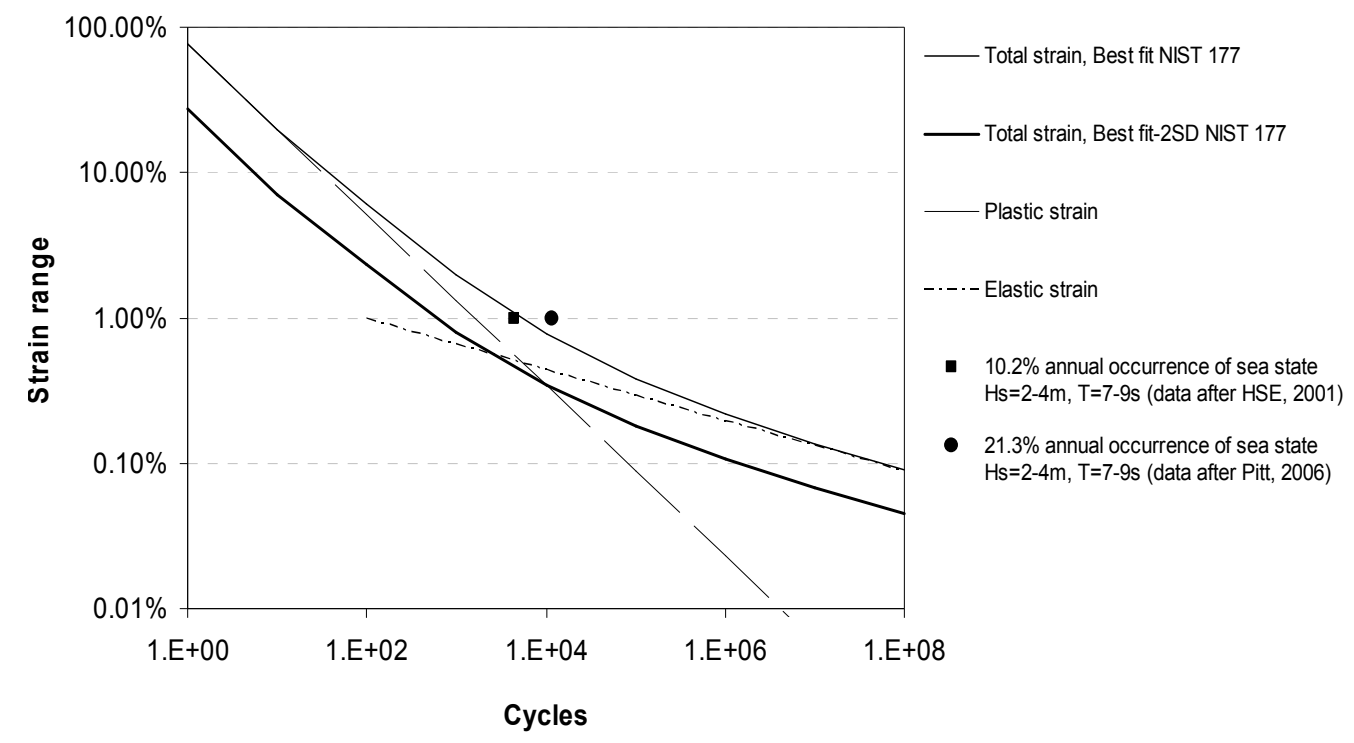

Figure 16: Strain - cycle $(\varepsilon-N)$ copper fatigue curve and expected number of conductor load cycles $>1 \%$ strain range for typical one year of operation (data: own calculations after $[28,13$, 14])

\section{Conclusion and further work}

The paper has assessed the expected loading regime of a typical marine power cable under dynamic conditions as they can be expected in a marine energy application. The fatigue life of the cable's copper conductor was estimated for the Wave Hub test site. Particular findings are: 
- Marine power cables have to withstand a dynamic loading regime when they are attached to wave energy converters and are susceptible to fatigue failures. The modelled conditions identify requirements for bend stiffener design.

- The number of load cycles was not simply estimated by considering a single DOF, but is a result of the combined motions in six DOF. The number of cycles calculated from a single DOF can be seen to be a 'lower bound'.

- Irregular sea states tend to induce higher loads and more fatigue cycles than regular sinusoidal sea states with the same wave parameters, due to the statistical distribution of wave elevations with larger values.

- The lazy wave shape reduces maximum tension forces, avoids compression and has fewer fatigue cycles and is deemed more suitable for the modelled conditions. As fatigue damage is a function of stress range (i.e. loading) a reduction in load implies a considerable increase of fatigue life of at least the power of 3.

In more general terms, the applied methodology combining i) experimental tank tests, ii) numerical modelling and iii) site specific characteristics has been described to estimate the environmental loading conditions of components in the absence of field experience and data. As a result the necessary design data can be enhanced and an initial estimate of the operational lifetime can be made prior to deployment in testing, yet unchartered dynamic conditions.

Real measurements from realistic sea trials would enhance the presented work by providing realistic forces and load cycles and the possibility to validate the numerical findings. This is part of ongoing work to reduce the assumptions made in the numerical model [5]. Moreover, physical component testing under operational loads and accelerated load conditions is envisaged to verify component reliability prior to field deployment. This would help to prevent expensive field failures as early failures could be revealed in a controlled environment and the most suitable component type/design option could be identified through comparative tests. The establishment of these so-called service simulation tests is also part of ongoing work [6, 7] 


\section{Acknowledgments}

The first author would like to acknowledge the funding support from the Engineering and Physical Sciences Research Council (EPSRC) under the SUPERGEN Marine Doctoral Programme and the supervision by Prof. G.H. Smith, Dr. L. Johanning and Prof. J. Wolfram. The laboratory work described in this publication was supported by the European Community's Sixth Framework Programme through the grant to the budget of the Integrated Infrastructure Initiative HYDRALAB III, Contract no. 022441 (RII3). Thanks also to Orcina for provision of their Orcaflex software. 


\section{References}

[1] Worzyk, T. Submarine Power Cables: Design, Installation, Repair, Environmental Aspects. Springer Series: Power Systems, Springer, 2009.

[2] De Alegria, I.M, Martin, J.L, Kortabarria, I., Andreu J. and Ereno, P.I. Transmission alternatives for offshore electrical power. Renewable and Sustainable Energy Reviews , 2009, 13, pp. 1027-1038.

[3] Green, J. Bowen, A., Fingersh, L.J. and Wan, Y. Electrical Collection and Transmission Systems for Offshore Wind Power. Proc. Offshore Technology Conference, Houston, Texas, 2007. National Renewable Energy Laboratory, Conference Paper NREL/CP-50041135

[4] Johanning, L., Smith, G.H and Wolfram, J. Mooring design approach for wave energy converters, Proc. IMechE Vol. 220 Part M: J. Engineering for the Maritime Environment, 2006, pp. 159-174.

[5] Johanning, L., Thies P.R. and Smith, G.H. Component test facilities for marine renewable energy converters. Proc. Int. Conf. Marine renewable and offshore wind energy, 2010, The Royal institution of Naval Architects (RINA), London, 21-23 April, pp. 35-46.

[6] Thies, P.R., Johanning, L. Development of a marine component testing facility for marine energy converters. Proc. 3rd International Conference on Ocean Energy (ICOE), 2010, Bilbao, Spain $6^{\text {th }}$ October

[7] Thies, P.R., Johanning, L. and Smith, G.H. Towards component reliability testing for Marine Energy Converters. Ocean Engineering, 2010, in press, available online, doi:10.1016/j.oceaneng.2010.11.011

[8] JDR. Dynamic power umbilical for wave energy buoy. Available at: http://www.jdrcables.com/SubseaPowerCables/RenewableEnergySolutions (accessed $17 / 11 / 2010)$

[9] Clausen, T. and D'Souza, R. Dynamic risers key component for deepwater drilling, floating production. Offshore magazine, May 2001 
[10] International Umbilical Manufacturers' Federation UMF. Experience report. Control umbilicals delivered by UMF members in the period 1995-2000, 2004.

[11] Patel, D. Subsea Umbilicals and Power Cables. STEEGE Lecture 44, 10th April 2008. www.braemarsteege.com/lecturenotes/lecture44.pdf

[12] Penrose, R., Elliott, A., Henden, E. Rainbow, B. and Hanham, J. Wave Hub Hydrographic Survey for Archaeological Assessment. 2009, Technical report by EMU for Halcrow, Report No. 08/J/1/02/1329/0829, available at: http://www.wavehub.co.uk (accessed 17/11/2010)

[13] Health \& Safety Executive [HSE]. Wind and wave frequency distributions for sites around the British Isles, 2001, report prepared by Fugro GEOS, Offshore technology report 2001/030.

[14]Pitt, E.G., Saulter, A. and Smith, H. Review of Wave Power ClimateThe wave power climate at the Wave Hub site. 2006, Applied Wave Research report to the SWRDA.

[15] Trarieux, F., Lyons, G.J. and Patel, M.H. Investigations with a bandwidth measure for fatigue assessment of the Foinaven dynamic umbilical including VIV. Engineering Structures, 2006, 28, pp. 1671-1690.

[16] Martinelli, L., Lamberti, A., Ruol, P., Ricci, P., Kirrane, P., Fenton, C. and Johanning, L. Power Umbilical for Ocean Renewable Energy Systems - Feasability and Dynamic Response Analysis. Proc. 3rd Int. Conference on Ocean Energy, 2010, Bilbao, Spain.

[17] Falcao, A.F. Wave energy utilization: A review of the technologies. Renewable and Sustainable Energy Reviews, 2010, 14, 3, pp. 899-918.

[18] Ashton, I., Johanning, L. and Linfoot, B. Measurement of the effect of power absorption in the lee of a wave energy converter. Proc. of the ASME $200928^{\text {th }}$ Int. Conf. on Ocean, Offshore and Arctic Engineering (OMAE), 2009, OMAE2009-79793, Hawaii, USA.

[19] Chakrabarti, S.K. Offshore Structure Modelling. 1994, Advanced Series on Ocean Engineering - Vol. 9, World Scientific Publishing, London.

[20]Huang, S. Stability analysis of the heave motion of marine cable-body systems. Ocean Engineering, 1999, 26, pp. 531-546.

[21] Orcina. OrcaFlex Manual. 2010, Version 9.4a, www.orcina.com 
[22] Randolph, M. and Quiggin, P. Non-linear hysteretic seabed model for catenary pipeline contact. Proc. of the ASME $200928^{\text {th }}$ Int. Conf. on Ocean, Offshore and Arctic Engineering (OMAE), 2009, OMAE2009-79259, Hawaii, USA.

[23] Schijve, J. Fatigue of structures and materials, Springer, 2009.

[24] Goel, H. D. Integrating reliability, availability and maintainability (RAM) in conceptual process design, 2004, PhD thesis Delft University, DUP Press.

[25] Det Norske Veritas (DNV). Recommended Practice DNV-RP-F205: Global Performance Analysis of Deepwater Floating structure. 2004.

[26] Lane, M., McNamara, J.F., Gibson, R. and Tyrer, A. Bend stiffeners for flexible risers, Offshore Technology Conference (OTC), 1995, 7730-MS.

[27] Mendenhall, H. and Schmidt, R.F. Copper and its alloys. In Kutz, M. (ed) Handbook of Materials Selection. 1998, John Wiley \& Sons.

[28] Karlsen, S., Slora, R, Heide, K., Lund, S. Eggertsen, F. and Osborg, P.A. Dynamic Deep Water Power Cables. 2009 RAO/CIS Offshore, pp.184-203.

[29] Simon, N.J., Drexler, E.S. and Reed, R.P. Properties of copper and copper alloys at cryogenic temperatures. 1992, NIST Monograph 177, National Institute of Standards and Technology.

[30] Knapp, R H; Das, S. and Shimabukuro, T A. Computer-aided design of cables for optimal performance. Sea Technology, July 2002.

[31]Ekeberg, K.I.; Ottesen, T and Aarstein, J., Predicting, measuring and implementing friction and bending stresses in dynamic umbilical design. Proc. Offshore Technology Conference, 2006, Paper Nr. 17986-MS

[32] Bruhns, O.T. Advanced mechanics of solids. 2003, Springer.

[33] WAFO-group. WAFO - A Matlab toolbox for analysis of random waves and loads - a tutorial. 2000, Center for Mathematical sciences, Lund University, Lund, Sweden.

[34] Rychlik I. A new definition of the rainflow cycle counting method. Int. J. Fatigue, 1987, 9, pp. 119-121.

[35] Brooke, J. Wave energy conversion. 2003, Elsevier. 


\section{List of Figures and tables}

Figure 1: Example of HVAC (3.3kV) subsea power umbilical (courtesy of JDR [8])

Figure 2: Standard flexible riser configurations for floating offshore structures [9]

Figure 3: Methodology to assess component reliability in marine environment

Figure 4: Wave climate characteristics at the Wave Hub site (adapted from [14])

Figure 5: Experimental setup and mooring dimensions [mm] of generic floating OWC. Left elevated view; Right - instrumentation and plan view.

Figure 6: Sample section for six degree of freedom motion response. Top - wave elevation. Three lower plots - translational/rotational displacement for each axis. Left ordinate translational movements $(X, Y, Z)$; Right ordinate - Rotational movements $\left(\theta_{X}, \theta_{Y}, \theta_{Z}\right)$.

Figure 7: Orcaflex model of armoured umbilical in catenary (left) and lazy wave configuration (right) attached to buoy having six degrees of freedom

Figure 8: Minimum, mean and maximum tension (compression) along the length of the umbilical $(\mathrm{Hs}=3.5 \mathrm{~m}, \mathrm{~T}=8 \mathrm{~s})$ Left - catenary; right - lazy wave configuration

Figure 9: Time series of the effective tension $0.5 \mathrm{~m}$ off the attachment point. Left - catenary; right - lazy wave configuration. N.B. different scales of y-axis

Figure 10: Maximum tension forces $(0.5 \mathrm{~m}$ off attachment point) for different wave heights and cable configurations

Figure 11: Minimum bending radius ( $0.5 \mathrm{~m}$ off attachment point) for different wave heights

Figure 12: Rainflow half cycles of lazy wave configuration for different wave periods (regular sea states, $\mathrm{Hs}=2 \mathrm{~m}$, calculated $0.5 \mathrm{~m}$ off attachment point, duration of $25 \mathrm{~min}$ ).

Figure 13: Strain-cycle $(\varepsilon-N)$ fatigue curve for copper conductor (reproduced from Karlsen [28]. Graph shows results from Simon et al. [32] for different copper qualities (under stress and strain controlled conditions) and results from rotational fatigue tests by [28] 
Figure 14: Umbilical strain time series ( $0.5 \mathrm{~m}$ off the attachment point, for outer diameter).

Worst $Z Z$ strain relates to the maximum sum of tensile and bending strain.

Figure 15: Rainflow strain cycle analysis of cable conductor strain cycles (lazy wave geometry) before (left) and after filtering with a threshold of $1 \%$ strain range (right).

Figure 16: Strain - cycle $(\varepsilon-N)$ copper fatigue curve and expected number of conductor load cycles $>1 \%$ strain range for typical one year of operation (data: own calculations after $[28,13$, 14])

Table 1: Mechanical failure modes of umbilicals (after Patel [11]) and applicability to marine energy converters

Table 2: Annual occurrence probability of modelled seastates

Table 3: Characterisation data for modelled umbilical (armoured cable properties after [16]; connection stiffness [22])

Table 4: Rainflow halfcycles for motion response of the device and umbilical tension/bending cycles near attachment point. Length of the simulation is $135 \mathrm{~min}$; irregular waves with $\mathrm{Hs}=3.5 \mathrm{~m}, \mathrm{~T}=8 \mathrm{~s}$.

Table 5: Strain cycles (exceeding 1\% range) for copper conductor in lazy wave double armoured umbilical - experimental tests and annual accumulated cycles for seastate at Wave Hub site. 